\title{
EFFECT OF MOULD TYPE AND SOLIDIFICATION TIME ON BIFILM DEFECTS AND MECHANICAL PROPERTIES OF AL-7SI-0.3MG ALLOY CASTINGS
}

\author{
MAHMOUD AHMED EL-SAYED ${ }^{1} \&$ KHAMIS ESSA ${ }^{2}$ \\ ${ }^{1}$ Department of Industrial and Management Engineering, Arab Academy for Science, \\ Technology and Maritime Transport, Egypt. \\ ${ }^{2}$ School of Mechanical Engineering, University of Birmingham, UK.
}

\begin{abstract}
The properties of light alloy castings are strongly affected by their inclusion content, particularly double oxide film defects (bifilms), which not only decrease the tensile and fatigue properties, but also increase their scatter. Recent research has suggested that oxide film defects may alter with time, as the air inside the bifilm would react with the surrounding melt, while the hydrogen dissolved in the melt could diffuse into the bifilm cavity to form hydrogen porosity. The mechanical properties of the casting were shown to be significantly dependent upon the new morphology of its entrained bifilms. In this work, the Weibull moduli of the tensile properties of three Al castings, all expected to contain oxide films of, approximately, the same amount were compared. The first casting was poured into a resin-bonded sand mould while the second and third castings were poured into ceramic moulds with the mould for the third casting being preheated prior to pouring. The results of mechanical property analysis and electron microscopy examination suggested a considerable influence of the type of the mould and the solidification time on the morphology of bifilms and by implication, on the reliability and reproducibility of the tensile properties.
\end{abstract}

Keywords: bifilms, castings, mechanical properties, oxide film defects

\section{INTRODUCTION}

During the casting of aluminium alloys, the melt surface is exposed to air, which results in the formation of a surface oxide film. As a result of surface disturbance, such as during metal transfer and pouring, the oxidised melt surface can be folded over onto itself and trap a layer of the mould atmosphere, creating a bifilm defect $[1,2]$. This defect can be incorporated into the bulk liquid by entrainment.

Double oxide film defects lower mechanical properties, but also lead to variable mechanical properties, contributing to the scatter of properties associated with shape castings [2,3]. Apart from their effect on mechanical properties, double oxide film defects have also been held to contribute to the formation of other defects, such as hydrogen porosity and intermetallic phases [2]. Their effect on the mechanical properties of the final casting depends upon several factors, such as their initial size, subsequent changes in size and volume due to melt conditions such as velocity and bulk turbulence, solidification time and hydrogen content of the melt.

Once a double oxide film defect has become incorporated into the melt, it would be expected to contain an atmosphere that would be predominantly air, which would be expected to react with the surrounding liquid metal. It was suggested by Nyahumwa et al. [4], Raiszadeh and Griffiths [5], El-Sayed et al. [6, 7] and Griffiths et al. [8,9] that the internal atmosphere of bifilms would react with the surrounding liquid $\mathrm{Al}$, forming different $\mathrm{Al}$ oxides and $\mathrm{AlN}$, and therefore was gradually consumed over time. Also, hydrogen was found to diffuse into the bifilm as the melt was kept longer in the liquid state. The consumption of the bifilm interior atmosphere as well as the $\mathrm{H}$ ingress into the defect was suggested by El-Sayed et al. to 
result in an alteration of the shape and size of the bifilm with a direct effect on the mechanical properties of the casting $[11,12]$. This change in morphology with time suggested that the defect could perhaps become less detrimental to mechanical properties.

The aim of this work was to study the effect of the type of the mould and the solidification time of the casting on entrained double oxide films, and the corresponding change in mechanical properties of aluminium alloy castings. Understanding these issues could lead to the development of techniques by which the effect of double oxide film defects in aluminium castings might be reduced or eliminated.

\section{EXPERIMENTAL WORK}

Three casting experiments were carried out to obtain tensile test bars with approximately similar bifilm content but with different bifilm ages and/or H content. In each experiment, two top-pouring moulds with a rectangular mould cavity of $120 \mathrm{x} 100 \mathrm{x}$ $20 \mathrm{~mm}$, each producing 10 test bars, were used. In the first experiment, in which castings with relatively high $\mathrm{H}$ content were expected, resin bonded sand moulds were prepared one day before the casting experiment. In the second experiment, two ceramic shell moulds were produced via investment casting technique. The moulds were then dried prior to pouring, which was carried out while the moulds were at room temperature. The third experiment was exactly same as the second one except that the ceramic moulds were preheated to $800^{\circ} \mathrm{C}$ prior to pouring. Ceramic moulds were used in the second and third experiments instead of sand moulds to prevent the solidifying casting from picking up $\mathrm{H}$ from the solvent of the resin used as a binder for the sand moulds.

In each experiment, about $7 \mathrm{~kg}$ of $2 \mathrm{~L} 99$ alloy $(\mathrm{Al}-7 \mathrm{Si}-0.3 \mathrm{Mg})$ was melted in an induction furnace and then was held at $800^{\circ} \mathrm{C}$ under a vacuum of about 80 mbar for one hour, a procedure intended partially degas the molten metal [12] as well as to remove most, or all, previously introduced oxide films from the melt. The liquid metal was then poured from a height of about 1 meter into sand/ceramic moulds, which was expected to be sufficient for the creation and entrainment of new double oxide film defects, and their introduction into the melt.

For each experiment, two Leco samples for solid-state $\mathrm{H}$ determination were taken; one from the melt after vacuum treatment and before pouring, and the second sample was taken from the running bar of the castings. Both samples were analyzed to determine the hydrogen content of the castings. After solidification, each of the castings was machined into 10 tensile test bars with a gauge length of $90 \mathrm{~mm}$ and of a rectangular cross-section in the gauge length of $10 \times 7 \mathrm{~mm}$. They were pulled to fracture using a tensile testing machine model MTS 810, with a strain rate of $1 \mathrm{~mm} \mathrm{~min}{ }^{-1}$. Tensile results were evaluated using a Weibull statistical analysis approach to assess the influence of the different casting conditions on the variability of the mechanical properties of the castings. Finally, SEM with EDX analysis was used to investigate the fracture surfaces of the test bars.

For each of the three experiments, an extra mould was cast to measure the solidification time of the casting in each experiment. In each experiment a type K-Inconel-sheathed thermocouples (of $1 \mathrm{~mm}$ diameter and $500 \mathrm{~mm}$ length and with a maximum allowable temperature of $1100^{\circ} \mathrm{C}$ ) was inserted into the mould cavity. The thermocouples were connected to a data logger, which was used to record the change of temperature at the thermocouple tip with time at a rate of $1 \mathrm{~Hz}$. For each casting, the temperature recording was terminated when the casting temperature reached $610^{\circ} \mathrm{C}$, the liquidus temperature of the alloy. 


\section{RESULTS AND DISCUSSION}

This solidification time measurement experiment was carried out to determine the time taken for the aluminium castings poured into the ceramic and the sand moulds to solidify after casting. It was found that the solicitation times of the castings poured into the sand mould (experiment 1 ) and un-preheated ceramic mould (experiment 2 ) were about 5 and 10 seconds, respectively. However, in the third experiment, where the liquid $\mathrm{Al}$ was decanted into a preheated ceramic mould, the melt had taken about 230 seconds to reach the liquidus temperature (about $610^{\circ} \mathrm{C}$ ). Such significant difference in the solidification times would be due to the mould preheating prior to pouring. This could be helpful in determining more accurately the age of a double oxide film, or the time spent by the defect in the liquid metal before freezing.

The two-parameter Weibull distribution was used to analyze the scatter in the mechanical properties of the $\mathrm{Al}-5 \mathrm{Mg}$ alloy castings produced under different casting conditions, as it was suggested to be more appropriate than a normal distribution [13, 14]. The Weibull modulus (the slope of the line fitted to the log-log Weibull cumulative distribution data) is a single value that shows the spread of properties; a higher Weibull modulus reveals less variability among the studied property.

Weibull plots of the UTS and \% elongation of the test bars cut from the castings from the three experiments are shown in Figs 1 and 2, respectively. The values of the correlation coefficients $\left(\mathrm{R}^{2}\right)$ suggested that the data points expressing both the UTS and \% elongation values were linearly distributed. It was noted that for both the UTS and \% elongation, the Weibull moduli (the slope of the trend line) of the castings from experiment 3, where a preheated ceramic mould was used, were the highest among all castings.

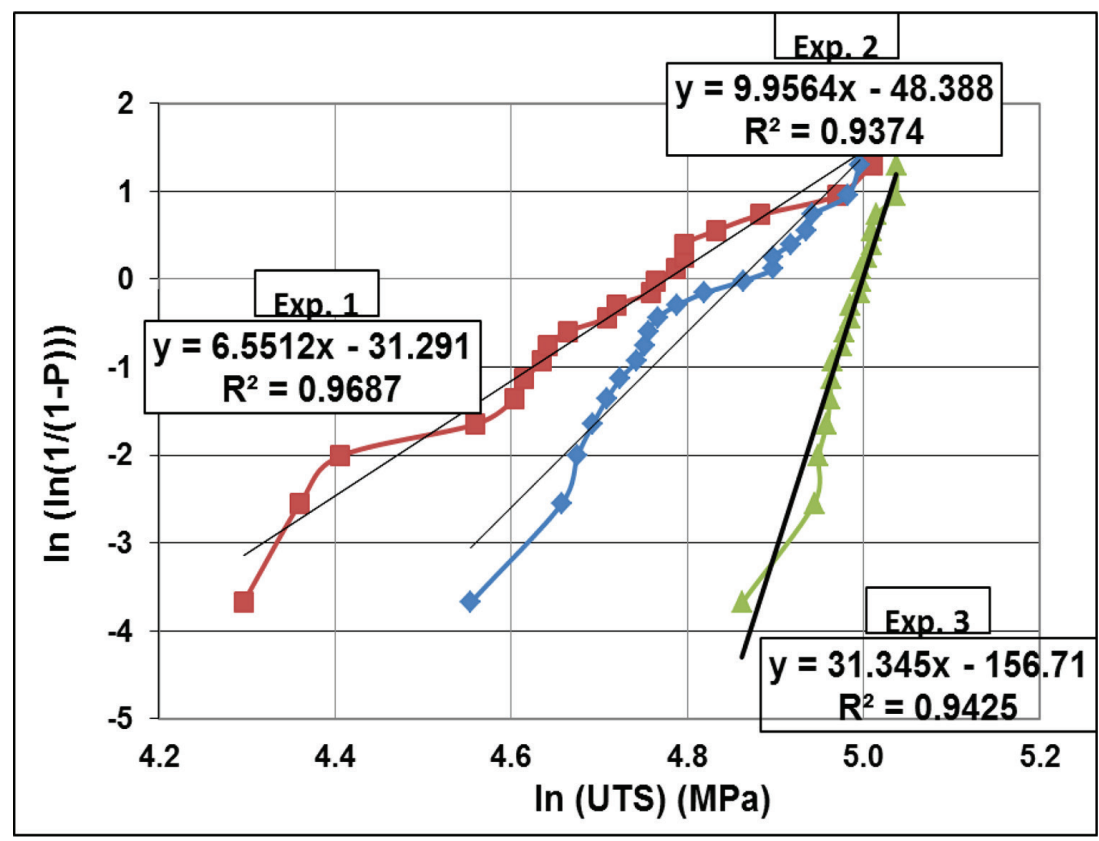

Figure 1: Weibull distribution of ultimate tensile strength of $\mathrm{Al}-7 \mathrm{Si}-0.3 \mathrm{Mg}$ alloy specimens from different experiments. 


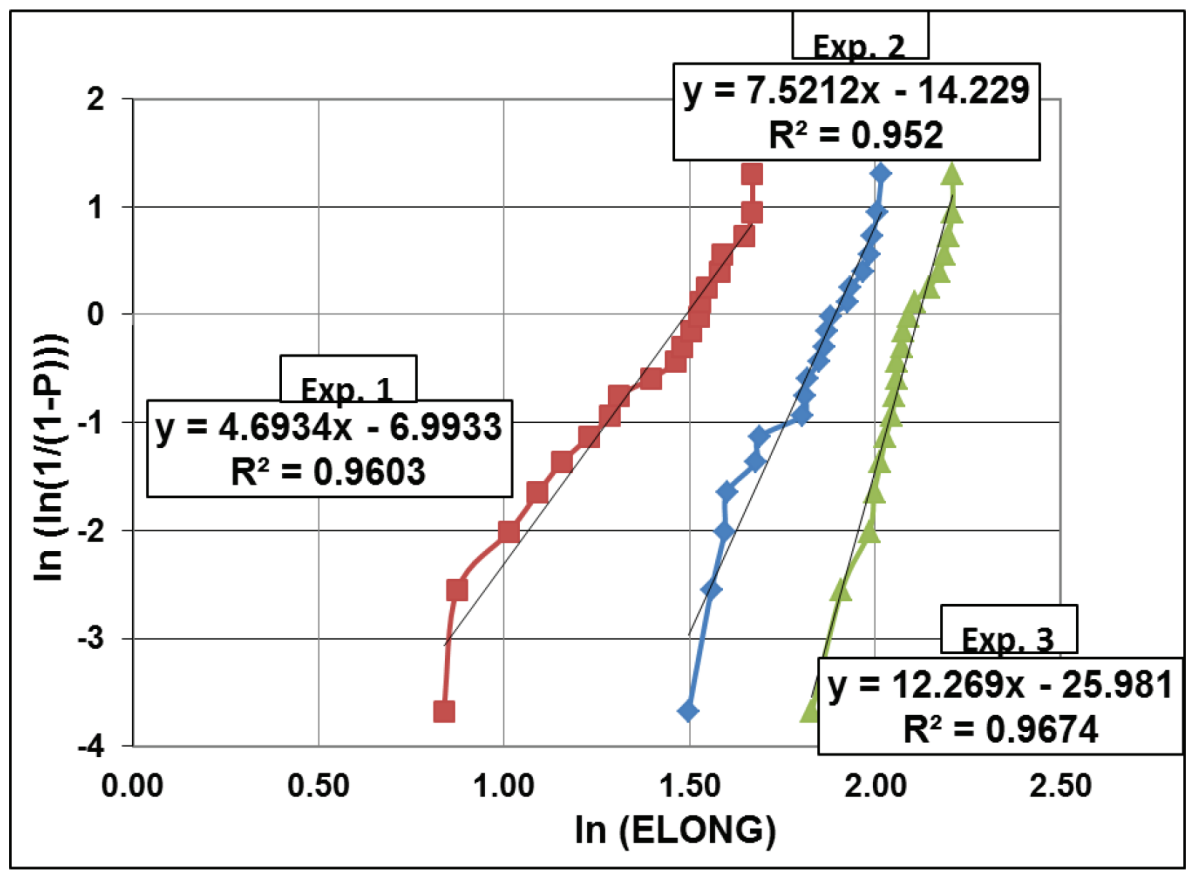

Figure 2: Weibull distribution of $\%$ elongation of $\mathrm{Al}-7 \mathrm{Si}-0.3 \mathrm{Mg}$ alloy specimens from different experiments.

Table 1 shows the results of the Weibull analysis of both of the UTS and percentage elongation values obtained from the different experiments, together with the position parameter and the results of $\mathrm{H}$ measurements from different experiments.

The H content of the Leco sample, taken from the melt before pouring, was $0.131 \mathrm{~cm}^{3} / 100 \mathrm{~g}$ Al. From the results presented in Table 1 It was found that, the $\mathrm{H}$ content of the solidified casting poured into the sand mould (experiment 1) was measured to be $0.235 \mathrm{~cm}^{3} / 100 \mathrm{~g} \mathrm{Al}$, almost twice the $\mathrm{H}$ content of the liquid casting, probably due to $\mathrm{H}$ pick-up from the resin-bonded sand moulds. However, the castings poured into ceramic moulds had $\mathrm{H}$ content of 0.139 and $0.152 \mathrm{~cm}^{3} / 100 \mathrm{~g}$, respectively for experiments 2 and 3 . In the second experiment (when the melt was poured into an un-preheated ceramic mould), the $\mathrm{H}$ content was almost the same as that of the melt before pouring, which was expected to be due to the almost

Table 1: Results of the $\mathrm{H}$ measurement and Weibull analysis for the test bars of the castings from different experiments.

\begin{tabular}{|c|c|c|c|c|c|c|c|}
\hline \multicolumn{3}{|c|}{ Casting Conditions } & \multirow{2}{*}{$\begin{array}{l}\text { H Content of } \\
\text { Solidified } \\
\text { Casting } \\
\left(\mathrm{cm}^{3} / 100 \mathrm{~g} \mathrm{Al}\right)\end{array}$} & \multicolumn{2}{|c|}{ UTS (MPa) } & \multicolumn{2}{|c|}{$\%$ Elongation } \\
\hline $\begin{array}{l}\text { Exp. } \\
\text { No. }\end{array}$ & $\begin{array}{l}\text { Mould } \\
\text { Material }\end{array}$ & Preheating & & $\begin{array}{l}\text { Weibull } \\
\text { Modulus }\end{array}$ & $\begin{array}{l}\text { Position } \\
\text { Parameter }\end{array}$ & $\begin{array}{l}\text { Weibull } \\
\text { Modulus }\end{array}$ & $\begin{array}{l}\text { Position } \\
\text { Parameter }\end{array}$ \\
\hline 1 & Sand & No & 0.235 & 6.6 & 118.9 & 4.7 & 4.4 \\
\hline 2 & Ceramic & No & 0.139 & 10.0 & 129.0 & 7.5 & 6.6 \\
\hline 3 & Ceramic & Yes & 0.152 & 31.3 & 149.4 & 12.3 & 8.3 \\
\hline
\end{tabular}


instantaneous solidification. In the third experiment (when the melt was poured into a preheated ceramic mould) the $\mathrm{H}$ content was slightly higher, perhaps due to the $\mathrm{H}$ pick-up by the casting from the surrounding atmosphere during solidification (which took about 4 minutes).

Oxide film defects were found on all the fracture surfaces of test bars investigated from both experiments 1 and 2. Figures 3(a) and (b) show examples of SEM images of oxide films found on the fracture surfaces of test bars from experiments 1 and 2 respectively. The corresponding EDX analysis suggested the presence of $\mathrm{MgAl}_{2} \mathrm{O}_{4}$ spinel on the surfaces. However, the size of oxide film in the specimen from experiment 1 was relatively larger than that in experiment 2. The oxide film in Fig. 3(a) is about 1.5 x $0.5 \mathrm{~mm}$, while that in Fig. 3(b) is about $0.3 \times 0.3 \mathrm{~mm}$ ), perhaps due to the larger $\mathrm{H}$ content of the formers.
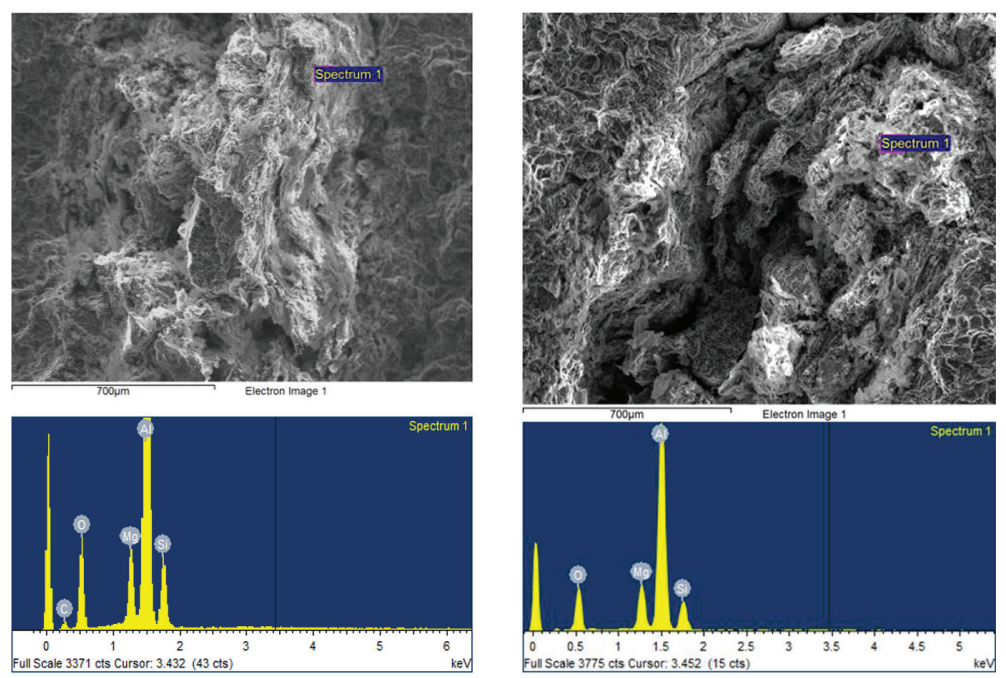

(a)

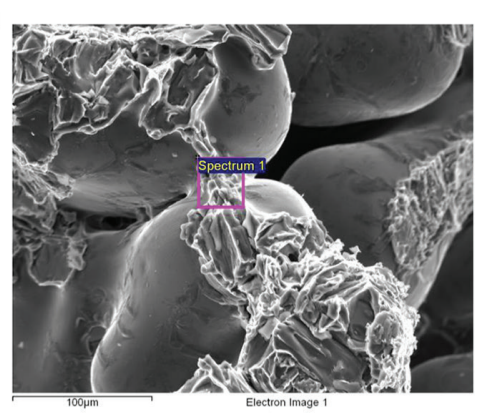

(b)

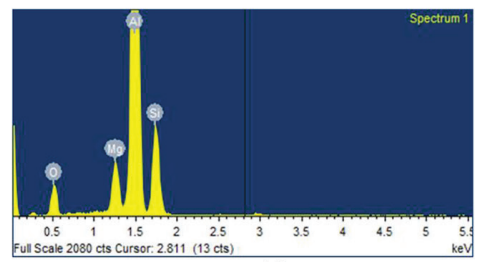

(c)

Figure 3: (a), (b) and (c) SEM images and corresponding EDX analysis of bifilms found at the fracture surfaces of test bars from experiments 1,2 and 3, respectively. 
Figure 3(c) shows an SEM image of a pore found on the fracture surfaces of a specimen from 2L99 alloy casting that was poured into preheated a ceramic mould and took about four minutes to solidify (experiment 3). Oxide films detected in this experiment were always found covering or trapped within the dendrites inside the pores. The EDX analysis suggested the existence of spinel, indicated by the $\mathrm{Mg}$ peak.

No other oxide films were found on the fracture surfaces of the test bars from all castings from experiment 3. The SEM images of the pores on the fracture surfaces of specimens from this experiment showed oxide layers with different forms inside these pores. The EDX analysis of these oxides indicated the presence of $\mathrm{MgAl}_{2} \mathrm{O}_{4}$, indicating that the origins of the pores were primarily oxide film defects that might have been changed their shapes and sizes during the solidification time to form pores. This might suggest a role of the time spent by the casting in the liquid state before solidification in eliminating bifilms in Al castings, or at least altering their morphology.

It has been suggested by Campbell [2] that, after entrainment and due to internal turbulence in the bulk liquid, the entrained film might become compacted in a convoluted form. Afterwards, and during solidification the bifilm might unfurl and its shape might then be changed to a planar crack or a pore. In addition, the results by Griffiths and Raiszadeh [15] and El-Sayed and Griffiths [12] suggested that both the solidification time of the casting and the $\mathrm{H}$ content of the melt can play a role in controlling the variability of the mechanical properties of Al castings.

In this experiment the tensile properties of three sets of 2L99 alloy castings with different $\mathrm{H}$ contents and/or solidification times were compared. The $\mathrm{H}$ content of the melt before pouring was $0.131 \mathrm{~cm}^{3} / 100 \mathrm{~g} \mathrm{Al}$. The castings from experiments 1 and 2, which were solidified almost instantaneously, had practically not allowed any time during solidification for the unfurling mechanism to take place and therefore the main difference between the two castings was the mould material. For the castings from experiment 1, poured into sand moulds made one day before the experiment, the high temperature during pouring would probably cause the solvent (of the resin bonding the sand grains) to evaporate and release hydrogen, which was absorbed by the liquid metal. This had significantly increased the $\mathrm{H}$ content of the solidified casting to $0.235 \mathrm{~cm}^{3} / 100 \mathrm{~g}$. In contrast, for the casting poured into un-preheated, but dried, ceramic mould did not cause such $\mathrm{H}$ pick up from mould walls which caused the $\mathrm{H}$ content of the solidified casting to be much lower $0.139 \mathrm{~cm}^{3} / 100 \mathrm{~g} \mathrm{Al}$, almost the same as the melt before pouring.

Dispinar and Campbell [16-19] suggested that hydrogen in excess of the solubility limit of the $\mathrm{Al}$ melt might diffuse into the bifilm gap to form $\mathrm{H}$ porosity in the $\mathrm{Al}$ castings. The same conclusion was reached by Raiszadeh and Griffiths [5].

Double oxide film defects should have been present in both castings from experiments 1 and 2 because of the poor running system design that was deliberately used, as was shown by the SEM investigation of the fracture surfaces, shown in Figs 3(a) and (b), respectively. However, the relatively lower $\mathrm{H}$ content of the casting in experiment 2 would have significantly reduced the amount of $\mathrm{H}$ diffused into the bifilms, decreasing their sizes and therefore enhancing the quality and reproducibility of the mechanical properties of the casting. Compared to experiment 1 , the casting from experiment 2 had the Weibull moduli of the UTS and $\%$ elongation improved by about $52 \%$ and $60 \%$, respectively, and the position parameters of both properties to increase by about $8 \%$ and $50 \%$, respectively.

When the melt was poured into a preheated ceramic mould, the $\mathrm{H}$ content of the final casting was $0.152 \mathrm{~cm}^{3} / 100 \mathrm{~g} \mathrm{Al}$. The slight increase in the $\mathrm{H}$ content, compared to experiment 2, 
could be perhaps due to the $\mathrm{H}$ pick-up by the casting from the surrounding atmosphere during solidification (which took about 4 minutes). The SEM investigation of the fracture surfaces of specimens from this experiment did not detect any oxide films lying on the surfaces. Instead, all of the oxide films were found within pores, as was confirmed by the EDX analysis that detected the presence of spinel inside pores, as shown in Fig. 3 (c). Also, the sizes of oxide films were significantly smaller than those in experiment 2, despite the nearly similar $\mathrm{H}$ contents of both castings. Finally, there was a noticeable improvement in the mechanical properties. Compared to experiment 2, the casting from experiment 3 had the Weibull moduli of the UTS and \% elongation to improve by about $213 \%$ and $64 \%$, respectively, and the position parameters of both properties to increase by about $16 \%$ and $26 \%$, respectively.

El-Sayed et al. [11] had suggested that during solidification the bifilms experienced two competing mechanisms. The first mechanism is the consumption of air inside the bifilms, and the other mechanism is the diffusion of $\mathrm{H}$ into the defects. Both mechanisms were expected to influence the morphology of the bifilm defects and by implication their effect on the mechanical properties of the casting. The solidification times of the castings in experiments 2 and 3 were about 10 second and 230 seconds respectively. Therefore, it could be suggested that during solidification of the casting in the preheated ceramic mould (experiment 3 ) some morphological changes occurred to the double oxide film defects. This could be perhaps due to the consumption of their interior atmospheres while a little amount of $\mathrm{H}$ was picked-up from the ceramic mould and/or the surrounding atmosphere (causing it to slightly increased from 0.131 to $0.152 \mathrm{~cm}^{3} / 100 \mathrm{~g} \mathrm{Al}$ ), which might have caused them to be less harmful to the mechanical properties.

To summarize, the Weibull analysis of the tensile properties of 2L99 casting specimens from different experiments, containing double oxide film defects with different ages (time taken during solidification) and/or $\mathrm{H}$ contents suggested the occurrence of two competing mechanisms that controlled the mechanical properties. The consumption of air inside the bifilms due to reaction with the surrounding molten metal may lead to improvements in mechanical properties, but this may be accompanied by hydrogen passing into the bifilms, which would have a deleterious effect on properties. Also, the melt was found to pick $\mathrm{H}$ from either the walls of sand moulds and surrounding air during solidification.

Therefore, if the $\mathrm{H}$ content of the melt could be decreased (by degassing) prior to pouring into a ceramic mould and then the filled mould could be held in a furnace with a dry atmosphere that contains the minimum possible water vapour content, this would allow a casting producer to benefit from the holding treatment in reducing the bifilm atmospheres (by reactions with the surrounding melt), while preventing the formation of $\mathrm{H}$ porosity. This would decrease the size of bifilm defects and in turn lead to castings with higher and more reproducible mechanical properties.

\section{CONCLUSIONS}

1. Oxide film defects were detected on all the fracture surfaces of the test bars from different experiments either lying on all the surfaces or inside pores, which demonstrated a role for such defects in influencing the failure of $\mathrm{Al}$ castings.

2. Increasing the $\mathrm{H}$ content of a $2 \mathrm{~L} 99$ casting from 0.139 to $0.235 \mathrm{~cm}^{3} / 100 \mathrm{~g} \mathrm{Al}$ increased the amount of $\mathrm{H}$ diffused into the bifilms, increasing their sizes and caused the Weibull moduli of both the UTS \% elongation to decrease by about $35 \%$.

3. Preheating of a ceramic mould to $800^{\circ} \mathrm{C}$ increases the solidification time of the casting which might allow the interior atmosphere of its entrained bifilms to react with the 
surrounding melt, reducing their sizes and accordingly their harmful effect on mechanical properties.

4. Not only the amount and age of oxide film defects but also the H content of the melt can determine the reliability and the reproducibility of the mechanical properties of Al alloy castings.

\section{REFERENCES}

[1] Campbell, J., Castings, 2nd. ed: Butterworth-Heinemann, 2003.

[2] Campbell, J., Entrainment defects. Materials Science and Technology, 22, pp. 127-145, 2006.

https://doi.org/10.1179/174328406x74248

[3] Basuny, F.H., Ghazy, M., Kandeil, A.-R.Y. \& El-Sayed, M.A., Effect of casting conditions on the fracture strength of Al-5 Mg alloy castings. Advances in Materials Science and Engineering, 2016, pp. 1-8, 2016. https://doi.org/10.1155/2016/6496348

[4] Nyahumwa, C., Green, N.R. \& Campbell, J., Effect of mold-filling turbulence on fatigue properties of cast aluminum alloys. AFS Trans, 106, pp. 215-223, 1998

[5] Raiszadeh, R. \& Griffiths, W.D., A method to study the history of a double oxide film defect in liquid aluminum alloys. Metallurgical and Materials Transactions B, 37(6), pp. 865-871, 2006.

https://doi.org/10.1007/bf02735007

[6] El-Sayed, M.A., Salem, H.A.G., Kandeil, A.Y. \& Griffiths, W.D., Determination of the lifetime of a double-oxide film in al castings. Metallurgical and Materials Transactions $B$, 45(4), pp. 1398-1406, 2014. https://doi.org/10.1007/s11663-014-0035-X

[7] El-Sayed, M.A., Salem, H.A.G., Kandeil, A.Y. \& Griffiths, W.D., A study of the behaviour of double oxide films in Al alloy melts. Materials Science Forum, 765, pp. 260-265, 2013.

https://doi.org/10.4028/www.scientific.net/msf.765.260

[8] Griffiths, W.D., Caden, A. \& El-Sayed, M., An investigation into double oxide film defects in aluminium alloys. Materials Science Forum, 783-786, pp. 142-147, 2014. https://doi.org/10.4028/www.scientific.net/msf.783-786.142

[9] Griffiths, W.D., Caden, A. \& El-Sayed, M.A., The behaviour of entrainment defects in aluminium alloy castings. Proceedings of the 2013 international symposium on liquid metal processing and casting, John Wiley \& Sons, Inc., pp. 187-192, 2013.

[10] El-Sayed, M., Hassanin, .H \& Essa, K., Effect of casting practice on the reliability of Al cast alloys. International Journal of Cast Metals Research, 29(6), pp. 350-354, 2016. https://doi.org/10.1080/13640461.2016.1145966

[11] El-Sayed, M.A., Salem, H.A.G., Kandeil, A.Y. \& Griffiths, W.D., Effect of holding time before solidification on double-oxide film defects and mechanical properties of aluminum alloys. Metallurgical and Materials Transactions B, 42(6), pp. 1104-1109, 2011. https://doi.org/10.1007/s11663-011-9571-9

[12] El-Sayed, M. \& Griffiths, W., Hydrogen, bifilms and mechanical properties of Al castings. International Journal of Cast Metals Research, 27(5), pp. 282-287, 2014. https://doi.org/10.1179/1743133614y.0000000113 
[13] Weibull, W., A statistical distribution function of wide applicability. Journal of Applied Mechanics, 13, pp. 293-297, 1951.

[14] Green, N.R. \& Campbell, J., Statistical distributions of fracture strengths of cast Al-7SiMg alloy. Materials Science and Engineering: A, 173(1-2), pp. 261-266, 1993. https://doi.org/10.1016/0921-5093(93)90226-5

[15] Griffiths, W.D. \& Raiszadeh, R., Hydrogen, porosity and oxide film defects in liquid Al. Journal of Materials Science, 44(13), pp. 3402-3407, 2009. https://doi.org/10.1007/s10853-009-3450-7

[16] Dispinar, D., Akhtar, S., Nordmark, A., Di Sabatino, M. \& Arnberg, L., Degassing, hydrogen and porosity phenomena in A356. Materials Science and Engineering: A., 527(16-17), pp. 3719-3725, 2010. https://doi.org/10.1016/j.msea.2010.01.088

[17] Dispinar, D. \& Campbell, J., Critical assessment of reduced pressure test. Part 1: porosity phenomena. International Journal of Cast Metals Research, 17, pp. 280-286, 2004.

https://doi.org/10.1179/136404604225020696

[18] Dispinar, D. \& Campbell, J., Use of bifilm index as an assessment of liquid metal quality. International Journal of Cast Metals Research, 19(1), pp. 5-17, 2006. https://doi.org/10.1179/136404606225023300

[19] Dispinar, D. \& Campbell, J., Effect of casting conditions on aluminium metal quality. Journal of Materials Processing Technology, 182(1-3), pp. 405-410, 2007. https://doi.org/10.1016/j.jmatprotec.2006.08.021 